\title{
Marketing communication in Tourism Connection challenges in new service sectors
}

\author{
Nicolae Al. POP \\ The Bucharest University of Economic Studies, Bucharest, Romania \\ Nicolae_al_pop@yahoo.com

\section{Cristina Andrada BABA} \\ The Bucharest University of Economic Studies, Bucharest, Romania \\ baba.andrada@gmail.com

\section{Raluca NĂSTATE ANYSZ} \\ The Bucharest University of Economic Studies, Bucharest, Romania \\ raluca.nastase.anysz@gmail.com
}

PICBE |

1098

\begin{abstract}
The drive for sensational, adventurous and unique experience is a growing tendency in contemporary society. Services adapt to this demand and communication is a main tool of support for these redefined services. Communication can redefine every known type of service by shaping expectations regarding interaction among parties, place of action, time of use, management methods, results and purpose of the information. The mass tourism is evolving into a variety of forms and one of the segments growing in importance is the Adventure tourism which requires, along with the complex and demanding activity, a more specific and canalized interaction on all levels and in all stages. The perception of an activity or a place, the gained support, the safety measures, emergency situations and general opinion are results of the marketing communication. This study observes the Adventure market in terms of reasons, types and trust, by leading a qualitative exploratory research and in-depth interviews with 18 actors and participants and expressing ways of adequate addressing. Romania is a newcomer on the Adventure tourism market and provides opportunities to test approaches.
\end{abstract}

Keywords: Marketing, Communication, Adventure Tourism

\section{Introduction}

Relationship marketing is the return of marketing at home. Gummesson (1999) points out that the essence of marketing (in the sense of the archaic relationship between buyer and seller, author's note) is precisely the mutually satisfactory exchange relationship. The "I win - you win" communication type and attitude are essential in this vision of things. Trust and commitment are essential conditions for building relationships (Pop, et.al., 2012; Hess, Sory, 2005; Delgado-Ballester, Munuera-Alemán, 2001; Duncan, Moriarty, 1998; Garbarino, Johnson, Morgan, Hunt, 1994; Peck, 1993,). These two factors determine customers to perform simple or repeated transactions (Berry, 1995; Webster, 1992). When referring to a brand, consumers place "feeling valued" and "trust" as key factors (Keller, 2011).

A crucial factor in building a relationship is the dialogic communication (Pang et al., 2018), which is the "negotiated exchange of ideas and opinions" (Kent, Taylor, 1998, p. 325) and refers to the efforts made to relate to the other through dialogue, communication and openness (Bortree, Seltzer, 2009). It is similar to the use of dialogue in interpersonal relationships (Taylor, Kent, White, 2001). Research shows that trust increases with mutual 
communication (Hammick and Ju, 2018; Fisman and Khanna 1999), as well as with the greater frequency of interaction between the two sides (Burt and Knez, 1996).

\section{Literature review}

\section{Communication and Marketing in Adventure Tourism}

The communication about services, especially for services such as adventure tourism, differs from the communication about goods, due to the intangibility of services (Hill, Gandhi, 1992) and a higher perception of the risk stemming from this intangibility (Mortimer, 2002). Marketing in adventure tourism has to show benefits that are more of the nature of an experience than of a material nature. However, as Hirschman (1980) presents, tangible attributes are more objective than intangible because they are revealed to the consumer through the senses, while the intangible attributes are a projection of the consumer's mind. Five main methods of tangibility have been identified (Mortimer, 2002, 2008; Mittal, 1999, 2002; Hill, Gandhi 1992): (1) the use of data and documents that highlight the benefits of the service and its competitive advantage; (2) exemplifying the context of the service, such as its use and sale; (3) highlighting physical components indissolubly related to service (Mittal, Baker, 2002), such as an airplane for an airline, a hotel bedroom, a reading room for a university, etc.; (4) the use of a strong brand image (Pina et al., 2006; Brodie, Whittome, Brush, 2009).

When it comes to service providers, emotional messages are more effective in promoting a favorable attitude (Mattila, 1999). This is particularly true when it comes to experience-based services (Zhang et al., 2014), such as tourism. Décaudin and Lacoste (2018) studied the most effective strategies to promote services and concluded that the optimal strategy is to present the clients' profile in advertising. This is valid for both utility and hedonistic service sectors such as tourism. Showing a physical representation of the service has been identified as the second optimal strategy. It therefore appears that in the service sector it is essential to help the target audience identify themselves in an emotional and anticipative manner with the service presented.

Another factor influencing the brand communication, especially service brands, is culture. Understanding the differences in cultural consumption is essential for developing strategies for service organizations (Davis, Wang, Lindridge, 2008; Laroche et al., 2000). Culture can influence the efficiency of marketing for adventure tourism. Hirschman and Holbrook (1982) highlight these cultural differences in experience-based consumption. Depending on the country, there are perceptible differences in the reasons for hedonic consumption, the type of entertainment that is preferred, and the level of excitement expressed.

One of the most widespread cultural studies was developed by Hofstede (2011). Hofstede introduced six social dimensions, individualism / collectivism, long / short orientation, avoidance of uncertainty, distance from power, masculinity / femininity and indulgence / retention, to explain the differences between national cultures (Hofstede, Minkov, 2010). Social characteristics such as individualism, masculinity, short-term orientation, acceptance of insecurity and indulgence are favorable for the spread of adventure tourism (Pelau, Pop, 2018). In particular, individuals in high-indulgence societies tend to perceive leisure as a more important factor in life compared to individuals in societies with a high degree of retention (Hofstede, 2011). Enjoying the moment, enjoyment, fun, 
spending and consumption are values and behaviors encouraged in such companies. This is a fertile ground for the marketing of experience-oriented services (Pop, 2019), which aims to create pleasant, interesting and memorable consumer experiences through the provided products or services (Shobeiri et al, 2018; Mathwick, Malhotra, Rigdon, 2001; Pin, Gilmore, 1998, 1999; Schmitt, 1999). When basic needs, in the sense of Maslow's pyramid, are met, people pursue more than materiality. They want experience, uniqueness, revelation, excitement and a connection with individuals like them. There is, therefore, a series of sensory-emotional desires that add to the rational motivating incentives (Schmitt, 1999; Holbrook, Hirschman, 1982), as well as motivations related to identity and self-esteem.

The Holbrook value framework (1994) classifies values in intrinsic versus extrinsic and active versus reactive characteristics. Extreme values have utility purposes, while intrinsic values refer to "appreciation of an experience for its own sake", beyond its tangible results (Holbrook 1994, p. 40). Moreover, active values determine consumers to adopt a participatory attitude and a collaborative role in the consumption process, while reactive values translate into appreciation and understanding of consumer experience. Mathwick, Malhotra and Rigdon (2001) use this framework to introduce a scale of values called Experience Scale. It consists of the following types of values: aesthetic (intrinsic and reactive), playful (intrinsic and active), cost-effective in relation to investment (extrinsic and active) and qualitative, determining the excellence of services (extrinsic and reactive). These sets of values build the framework for communication of experience services and are relevant to adventure tourism.

Lorentzen (2009) analyzed the experience economy and concluded that economic development and revenue growth in developed countries allow individuals to spend more money on luxury, leisure and experiences. Moreover, he observed that the postmodern sociological tendency is to express his identity through experiences. Consumers in the postmodern era seek novelty and adventure (Gabriel, Lang, 1995) and attach importance to selfexpression, personal development and lifelong learning. This corresponds to the self-update level at the top of Maslow's pyramid mentioned above and addresses the postmodern need to give meaning to life (Norton, Pine, 2009).

From a psychological point of view, communication is important to the discipline of marketing because consumers do not necessarily behave rationally, but rather emotionally (Bıçakcıŏlu 2018, Schmitt 1999). Goods and services are purchased not only for their functionalities but also for their subjective significance (McCracken, 1986; Levy, 1959) and their hedonic value (Batra, Ahuvia, Bagozzi, 2012). Bıçakçığlu (2018) investigated the brand preferences and the behavioral outcomes, such as brand loyalty and human-to-human referral. The study concluded that a branded experience strengthens the consumer's feelings about that brand and that they are beginning to identify themselves with the specific brand. The virtuous circle has also been emphasized, since emotional attachment to a brand increases the consumer's intent to buy it again, accentuates loyalty and motivates them to recommend it to their social circle. In order to provide customers with significant experience and create a link to the brand, companies can choose strategies based on experience, such as the use of sensory experiences, authentic designs and the inclusion of emotion-triggering elements alongside brand image elements. In the case of adventure tourism, these strategies are affordable and recommendable. 
Interestingly, brand preferences that are not based on experience, also have as source the values, identity and attitudes communicated by that brand. Consumers prefer brands that correspond to their identity (Bıçakcioğlu, 2018). Overall, the emphasis on the relationship with the consumer promotes the loyalty and attraction of other consumers by using recommendations (Biçakcıoğlu, 2018).

A feature of the modern marketing in social networking era is the ability to get in touch at a one-on-one level with businesses, institutions, and personalities through the online environment. With the use of the Internet, communication patterns have changed in favor of better interaction with consumers and a greater voice for stakeholders in the decisionmaking process (Pang et al., 2018). The Internet has made it possible to mobilize citizens on social networks, as well as dialogue between companies and customers in the form of feedback, comments, complaints, tweets, etc. Studies show that organically generated communication by social media stakeholders creates added-value for organizations and has begun to shape their image more closely than the communication generated by the organizations themselves (Schivinski and Dabrowski, 2014). Despite this, organizations do not make full use of interactive capabilities, and rather prefer to hold speeches in front of their stakeholders, rather than talk to them (Vernuccio, 2014). The fear of a bad image or loss of control determines the organizations' hesitation to actively participate or to engage in an open way with the stakeholders (Vernuccio, 2014). Unilateral communication allows one to maintain control over transmitted messages, to the detriment of authentic interaction (Lovejoy, Waters, Saxton, 2012; Shin, Pang, Kim, 2015). This defensive approach can lead to situations where market opportunities are missed.

The impact of customer-to-client information, in the public space of social networks and specialized forums (a sort of "Facebook Radio" or "Forum Radio ") is strong. This way of communication has been identified as the most important way for managers to identify the loyalty and commitment of their consumers (Matos, Rossi 2008, quoted by Verma, Sharma, Sheth, 2016). The information is precious to the marketer and the manager because, as concluded by Palmatier, Dant, Grewal and Evans (2006), conflict has the strongest impact on consumer relationship parameters. In addition, there is a set of web pages and platforms that are dedicated to collecting customer feedback, such as Yelp or Tripadvisor, the result being an excellent and accessible tool for exploring customer opinion (De Baynast et al., 2017, p. 623).

The online environment is also subject to communication patterns. In order to form a lasting long-term relationship, brand interactions must convey human-like traits found in human-human interactions (Davis, Piven, Breazeale, 2014). This is true even for the content of web sites, where the use of social parameters, such as the language in which the text is written, vocal elements, interactivity, induce a social perception for the user, and lead to a positive experience (Wang et al., 2007). Online communication becomes more like face-toface communication (Hammick and Ju, 2018). The ideal type of online communication is characterized by a mutually balanced control between companies and consumers, which could be described as "mutual control." This is defined by Hon and Grunig (1999) as the degree to which the parties agree on who has the legitimate power to influence each other". Hon and Grunig (1999) argue that stable relationships require both organizations and the public to have some control over each other. A parallel could be drawn here with the division 
of powers within the state and with the mutual checks and balances maintained between these powers.

\section{Methodology}

This article analyzes the communication methods used in adventure tourism and their effect on the promotion of this type of tourism in Romania. The purpose of the article is to highlight the most effective communication methods that go beyond the classical channels and capture PICBE | the peculiarity of the studied subject. The investigative approach embraced the form of a qualitative exploratory research study.

The Inquiry Method, the in-depth interview technique, based on the Conversation Guide instrument (Fotea, 2012; Cătoiu et all, 2009; Plaçais et all, 2008) were used in the elaboration of the research. The 15 respondents analyzed the four proposed hypotheses using a conversation guide developed by the authors. The interviews took place between June and November 2018, and the respondents are Romanian citizens: five are actors / organizers of these activities, five are frequent practitioners, four are potential practitioners and one is a theorist in this field.

Hypotheses are formulated based on desk research by analyzing specialized studies and then tested with the interviewees. Respondents were given the opportunity to formulate their free answers according to which more specific questions were raised, reaching deeper levels to know the group's motivations and the role of emotions in the decision-making process. The assumptions used in the study were as follows.

\section{Results and discussions}

\section{H1: Communicating the psychological factors is more persuasive than communicating} the physical factors

Along with the development of the society, people seek experiences that go beyond the material area and aim for a series of sensory-emotional wishes. The rhythm of the big cities' inhabitants belonging to the middle and upper social class affects the identity and the selfesteem. The need for a group membership and self-exploration can be accomplished by several methods and adventure tourism is a solution that meets this need. However, to choose this form of self-indulgence to the detriment of another, the participants in the study emphasized in their quasi-totality that the organizers must firstly highlight the obtained benefits, which are of psychological, physical, communitarian and emotional nature. In different forms, which had a complementary character, the respondents pointed out that in adventure tourism the communication between the organizers of the tourist activities and the potential practitioners must include emotional messages, such as possible outcomes (e.g.: social causes of a marathon or contest, lifestyle-improvement) or impose a story-script, motivating through spectacularity and uniqueness. Practitioners of this type of tourism acknowledge that the main benefit they derive from these activities is of a psychological nature and they are more likely to be attracted by the results obtained, rather than the activity itself, which can be rather seen as a niche limited by inaccessibility or unawareness. The theoretician in the field confirms that the message contained in the communication must be verisimilar and address the large audiences. Based on all these arguments, it was appreciated that the $\mathrm{H} 1$ hypothesis was confirmed. 


\section{H2: Concrete communication, by exemplifying the context of the service and}

supporting it through studies, increases confidence in that form of tourism

If the interest and willingness to participate of potential practitioners are awakened so as to explore the option in detail, there is a new barrier when the activity itself is exposed to the public, which must also be overcome by correct and case-related communication. Many of the activities included in the package of adventure tours are little known to the general public PICBE | and create prejudices. Most interlocutors have pointed out that in adventure tourism the infact communication of activity, as usually done by experts and organizers, is not comprehensive and explicit enough, and the lack of detail distances potential practitioners. Referring to the practitioners of this form of tourism, respondents have confirmed that there is a major reticence over challenges taking place in unknown premises. Nevertheless, they say that they would be interested to try if they were guided in the discovery process through explanatory videos, through studies and if the organizers of the activity facilitate their learning process in a beginner friendly way. Some organizers prefer however to design programs during which activities are only revealed along the way, in order to enhance participants' astonishment. The desire of potential participants in tourism activities to prioritize this aspect is legitimate and it was supported by the majority of respondents in the study. Corroborating all the answers received, we can conclude accepting the $\mathrm{H} 2$ hypothesis.

\section{H3: The online environment, but especially sport/training communities, are the channels of adventure tourism distribution}

Adventure tourism is focused on the individual and on their own experiences, but the activity themselves are carried out in the community due to their complexity and high degree of risk. The created communities bring together people with common interests who form part-time partnerships through the trust that building up in the course of their activities.. The in-depth interview revealed that most respondents noticed the significance of the created communities (Facebook, Twitter, Instagram, etc.) as an essential factor in continuing to do an adventure tourism activity. The sense of belonging and the support of the group in achieving personal goals are factors that many people identify only through adventure activity. Thus, loyalty is created through the community much more than the tourism offer itself. The vast majority of respondents pointed out that in this sense communication is aimed at the individual when he tries to become a member of a community but at the same time, they are looking at a whole group when they want to organize a competition, or when a new opportunity is known. If the style of communication is consumer-oriented, including the psychological elements characteristic to the group and knowing its needs and the specificity of the activity, the means by which communication is achieved is the Internet. Possible adventure tourism practitioners and communities of these people are geographically dispersed and often meet only on the occasion of the activity themselves. For the decisionmaking process, the online environment serves as an instrument. Communication to this effect is done through web presentation pages, which must contain detailed and qualitative information, because in general it is a group decision, not an individual one, so each member of the group needs to be identify themselves with the offer. We also appreciate that the third hypothesis H3 is confirmed. 


\section{H4: A key element of communication is the transmission of information on investment and on the size of risks}

Although adventure tourism is meant to contribute to the recreation of the participants and is a leisure activity, its complexity requires preparation and evaluation, so that its actual development is only a part of the allocated time. Pre- and post-activity periods last between a few minutes (for lighter, commercial activities) and up to a few weeks or months (for example: before a meditation camp, marathon, triathlon, etc.). During this time, the connection between organizers and participants is virtual, but communication is also essential. The pre-activity period sparks the interest and motivation of the participant, it boosts their conviction of to prepare thoroughly and to choose the appropriate team and it enables the transmission of essential information for the success of the action. The postevent communication is crucial for the decision of the participants to stay close to the organizer or to recommend the product / service to others. From the interviews conducted, only a small part (less than one third) - mentions specifically that the sincere and loyal communication of the real size of the investment (monetary, physical and mental effort, etc.), as well as of the potential risks to which the participants may be exposed, plays an essential role in the overall success of the event. The fact that these content elements of communication with potential adventure tourism practitioners are not valued to their proper significance leads us to the belief that the fourth hypothesis $\mathrm{H} 4$ is invalidated.

\section{Figures and tables}

Figure 1: The communication steps to attract customers for Adventure tourism

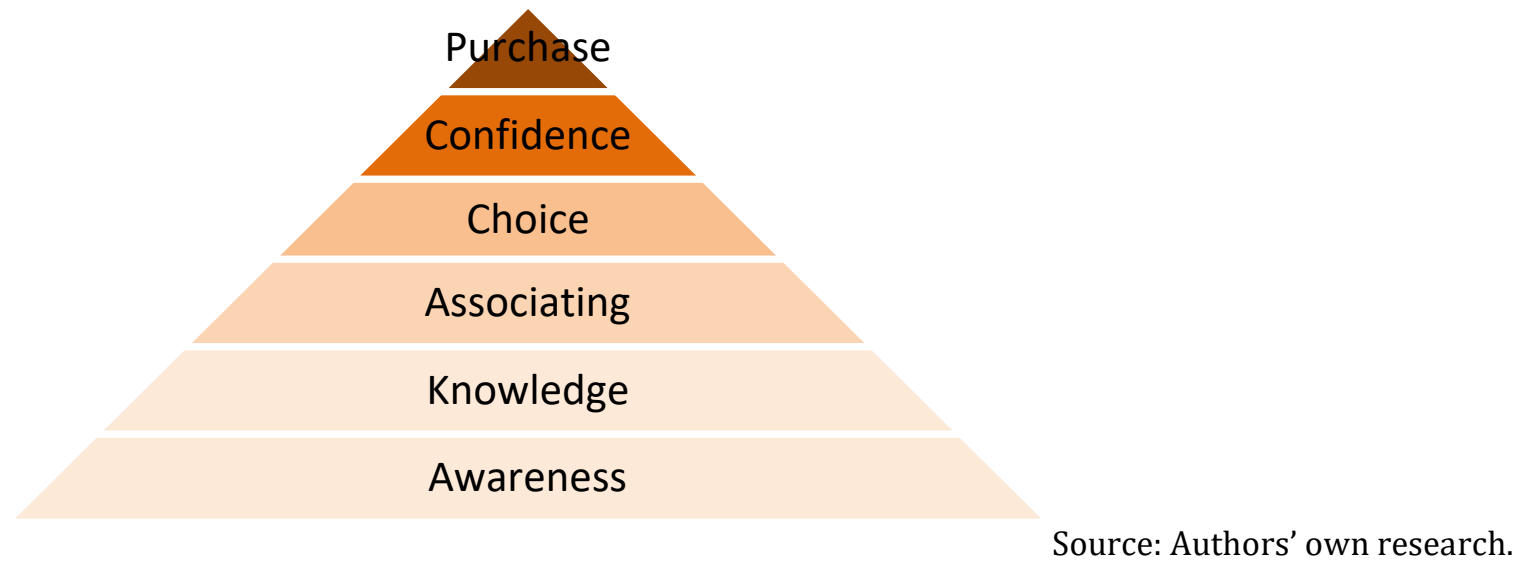

Figure 2: The most popular communication methods for Adventure travelers, expressed in \% 


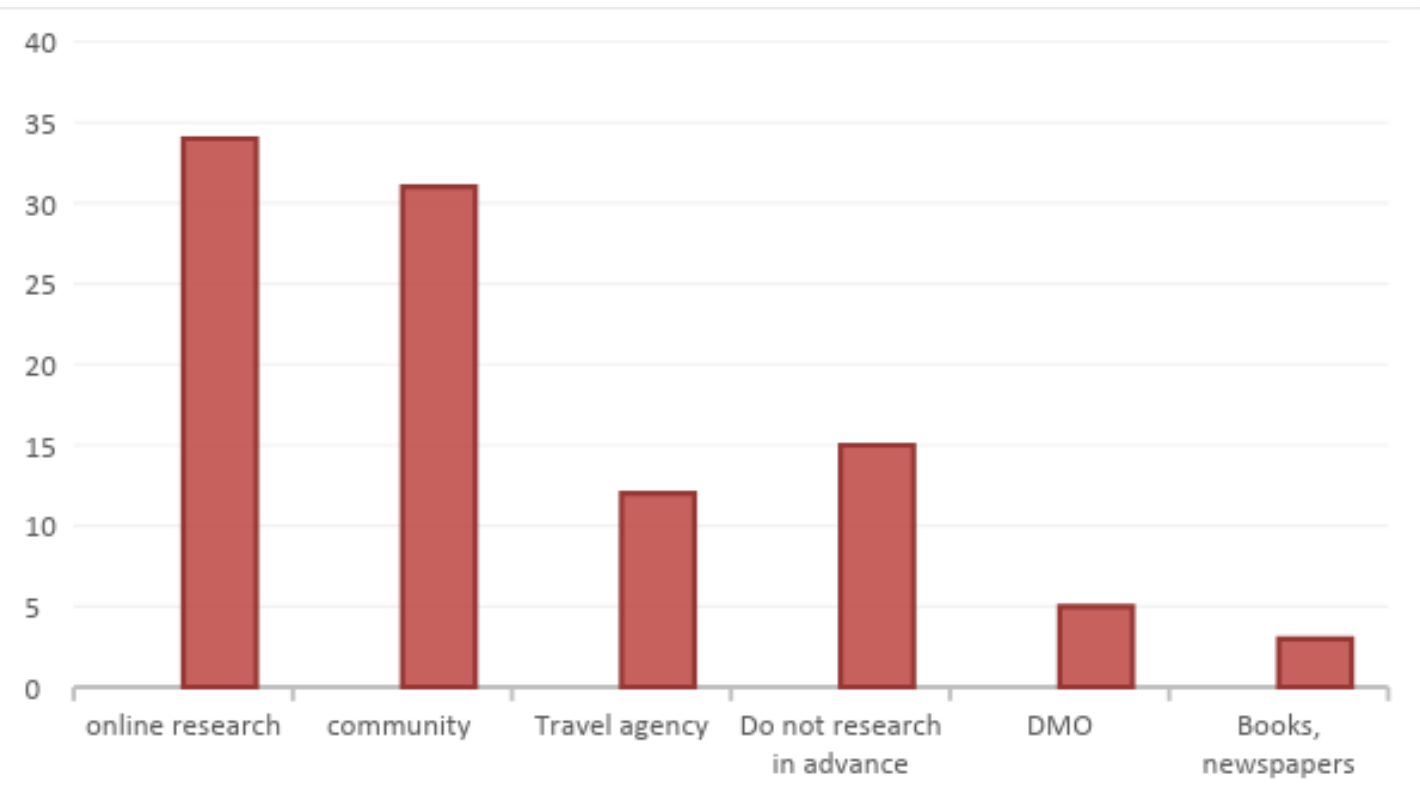

PICBE |

Source: Authors' own research.

\section{Conclusion}

Companies which are active in adventure tourism operate in an intangible, service-based sector. Their communication efforts must take into account the fundamental cultural aspects of their clients. Consideration must also be given to building relationships and generating positive recommendations through engagement and confidence. The positioning strategy will highlight lifestyle values, hedonistic features and identity expression. The use of online media is important, but it is essential to maintain a two-way communication flow that fosters dialogue and openness. The survey's clues highlight the need for a much better preparation of the adventure tourism offer from bidders in this category of services. It is also required to have a much clearer differentiation of this type of tourist offer compared to all other general tourist offerings. Differentiation is, in our opinion, one of the key elements that relational marketing contributes to an appropriate and specific positioning of this type of service. The training of specialists working in the field of design, realization of the human and material conditions of this type of tourism, as well as of those who are involved in the commercialization of specific offer packages is required in depth theoretically and methodologically (Dabija, Postelnicu, Pop, 2014) and not limited to the empirical experience gained in the field by those who want to promote this type of service. Communication with these services must not avoid emphasizing all the implications of the necessary investments and of the potential risks involved in practicing this type of tourism. The author's research is continued, in another study among practitioners of this type of activity in the form of quantitative selective, causal-descriptive research.

\section{References}

Augustine Pang, Wonsun Shin, Zijian Lew \& Joseph B. Walther (2018) Building relationships through dialogic communication: organizations, stakeholders, and computer-mediated communication, Journal of Marketing Communications, 24:1, 68-82 
Berry, L. L. (1995), Relationship Marketing of Services-growing Interest, Emerging Perspectives, Journal of the Academy of Marketing Science 23: 236-245.

Cătoiu, Iacob (coord.), (2009), Cercetări de marketing. - Tratat -, Editura URANUS, București.

Dabija, Dan-Cristian; Postelnicu, Catalin; Pop, Nicolae Al., (2014), Methodology for assessing the degree of internationalization of business academic study programmes, AMFITEATRU ECONOMIC, Volume: 16, Issue: 37, August, Pages: 726-745.

PICBE |

De Baynast, Armand \& Landrevile, Jaques \& Lévy, Julien (2017). Mercator. Tout le marketing 1106 à l'éra digitale, 12 édition, Dunod.

Delgado-Ballester, E., and J. L. Munuera-Alemán. 2001. "Brand Trust in the Context of Consumer Loyalty." European Journal of Marketing 35 (11/12): 1238-1258.

Duncan, T., and S. E. Moriarty. 1998. "A Communication-based Marketing Model for Managing Relationships." Journal of Marketing 62: 1-13.

Fotea, Ioan, Cercetări de marketing. O sinteză a procesului cercetării de marketing, (2013), Editura Universității EMANUEL, Oradea.

Garbarino, E., and M. S. Johnson. 1999. "The Different Roles of Satisfaction, Trust, and Commitment in Customer Relationships." Journal of Marketing 63 (2): 70-87.

Gummesson, Evert (2008). Total Relationship Marketing. Marketing management, relationship strategy, CRM, and a new dominant logic for the value-creating network economy, Third Edition, Elsevier.

Gummesson, Evert (2017) "From relationship marketing to total relationship marketing and beyond", Journal of Services Marketing, Vol. 31 Issue:1, pp.16-19.

Hess, J., and J. Story. 2005. "Trust-based Commitment: Multidimensional Consumer-brand Relationships." Journal of Consumer Marketing 22 (6): 313-322.

Jean-Marc Décaudin \& Denis Lacoste (2018) Services advertising: showcase the customer!, Journal of Marketing Communications, 24:5, 518-534,

Jinhyon Kwon Hammick \& Ilyoung Ju (2018) Facebook fan page: the effect of perceived socialness in consumer-brand communication, Journal of Marketing Communications, 24:7, 686-702 p.

Keller, E. (2011), Razorfish “Gasps": Consumer's aren't Feeling the Love from Facebook and Twitter, Accessed October 4, 2011. http://www.mediabizbloggers.com/edkeller/Razorfish-Gasps-Consumers-Arent-Feeling-the-Love-from-Facebook-andTwitter-Ed-Keller.html

Michael J. Valos, Paul Turner, Helana Scheepers \& Rosemary Stockdale (2018) Integrating online communities within business-to-business marketing communications: an exploratory study, Journal of Marketing Communications, 24:5, 450-468

Morgan, R. M., and S. D. Hunt, (1994), The Commitment-trust Theory of Relationship Marketing, Journal of Marketing 58: 20-38.

Nilay Bıçakcıŏlu, İlayda İpek \& Gül Bayraktaroğlu (2018) Antecedents and outcomes of brand love: the mediating role of brand loyalty, Journal of Marketing.

Peck, H., (1993), Building Customer Relationships through Internal Marketing: A State of the Art Review, Emerging Issues in Marketing, Proceedings of the 1993 Annual Conference of the Marketing Education Group, Loughborough University, Loughborough, UK, 797-813. 
Pelău, Corina, Pop Nicolae A., Implications for the energy policy derived from the relation between the cultural dimensions of Hofstede's model and the consumption of renewable energies, (2018), ENERGY POLICY, Volume: 118 July, Pages: 160-168.

Plăiaș, Ioan (coord.), (2008), Cercetări de marketing, Editura Risoprint, Cluj-Napoca.

Pop Nicolae A. , Quo Vadis Romanian Marketing: The Future and Contribution of the Romanian Community, (2019), CIVIL SOCIETY: THE ENGINE FOR ECONOMIC AND SOCIAL WELLBEING Book Series: Springer Proceedings in Business and Economics Pages: 119127.

Pop, Nicolae Alexandru; Roman, Mihaela; Saniuta, Adina; Petrișoaia Carmen,

Relationship Marketing, Engine of Sustainable Development and Orgnisational Change in the Romanian Business Environment, (2012), AMFITEATRU ECONOMIC, Volume: 14 Issue: 32, June, Pages: 349-364.

Saeed Shobeiri, Ebrahim Mazaheri \& Michel Laroche (2018) Creating the right customer experience online: The influence of culture, Journal of Marketing Communications, 24:3, 270-290.

Verma, Varsha Sharma, Dheeraj; Sheth, Jagdish (2016). Does relationship marketing matter in online retailing? a meta-analytic approach. Journal of the Academy of Marketing Science, Vol. 44(2), pp. 206-217.

Webster Jr, F. E. (1992), The Changing Role of Marketing in the Corporation Journal of Marketing 56: 1-17.

Zhang, Jonathan Watson, George F. Mmnmmiv; Palmatier, Robert W; Dant, Rajiv (2016). Dynamic Relationship Marketing, Journal of marketing, Vol. 80(5), pp. 53-75. 